\title{
Hoffnung für AML-Patienten
}

Leukämische Erkrankungen weisen eine ungünstige Prognose auf, können aber aus unterschiedlichen Gründen häufig nicht mit intensiven Maßnahmen behandelt werden. Hypomethylierende Therapien wie Azacitidin und Deciabine entfalten ihre Effekte durch eine Deaktivierung des Enzyms DNA-Methyltransferase und damit eine Reexpression der Tumorsuppressorgene, aber auch durch direkte Zytotoxizität. Azacitidin kommt in der Behandlung von Patienten mit AML und 20 bis $30 \%$ Knochenmarkblasten sowie Mehrlinien-Dysplasie laut WHOKlassifikation zur Anwendung und ermöglicht auch bei älteren und komorbiden Patienten eine signifikante Verbesserung des klinischen Verlaufs.

Das österreichische Azacitidin-Register zeigt die Effektivität von Azaciditin unter klinischen Alltagsbedingungen und ist gemessen an der Größe des Landes die weltweit größte derartige Datenbank, berichtet Dr. DI Lisa Pleyer, Universitätsklinik für Innere Medizin III, Landeskliniken Salzburg.

Seit wann wird das österreichische Azacitidin-Register geführt und wieviele Patienten sind derzeit darin erfasst?

Pleyer: Das Ethikkomissionsvotum wurde am 1. Februar 2009 erteilt. Seither wurden 622 Patienten ins Register eingeschlossen mit aktuell (17.07.14) 346 AML-Patienten, 56 CMML-Patienten und 220 MDS-Patienten.

Was zeigt sich darin speziell in Hinblick auf das Überleben von AML-Patienten mit 20-30\% Knochenmarksblasten?
Pleyer: Das mediane Überleben von AML-Patienten mit 20-30\% KM-Blasten $(n=100)$ beträgt 11,8 Monate.

\section{Welchen Unterschied sieht man bei} diesen Patienten je nachdem ob sie vorbehandelt wurden oder Azacitidin als Erstlinientherapie erhielten?

Pleyer: Patienten mit 20-30\% KMBlasten, die Azacitidin als Erstlinienbehandlung erhalten $(n=66)$, haben ein medianes Überleben von 14,3 Monaten, im Vergleich zu 6,0 Monaten von Patienten, die Azacitidin als Zweit oder Mehrlinientherapie erhalten $(n=34)$. Ein detaillierter Bericht über diese Patientenpopulation (WHO-AML mit 20-30\% KMBlasten), für die das Medikament derzeit zugelassen ist, ist für Herbst diesen Jahres in derWiener klinischen Wochenschrift geplant. 